\title{
Lateral Medullary Syndrome (Wallenberg'S Syndrome) - A Case Report
}

\author{
R Saha ${ }^{1}, \mathrm{~S}$ Alam ${ }^{2}$, MA Hossain ${ }^{3}$
}

\begin{abstract}
The Lateral medullary syndrome is not a very common stroke. Sometimes it is under diagnosed. Mr. Ibrahim Mollah, 50 years old male person, non diabetic, non hypertensive but smoker presented with the history of sudden onset of dysphagia, dysarthria and ataxia of the gait. He is clinically and radiologically diagnosed as a case of Lateral medullary syndrome (Ischaemic stroke). With treatment this patient improved significantly. It is commonly caused by occlusion of the cranial segment of the vertebral artery or the posterior inferior cerebellar artery. The occlusion may be due to thrombosis or embolism. The emboli are coming from the heart or the great vessels. We can diagnose Lateral medullary syndrome with expert clinical eye and CT/MRI of the brain. It should be managed with appropriate treatment and physiotherapy.
\end{abstract}

\section{Introduction}

The Lateral medullary syndrome was first descried in 1808 by Gaspard vieussux ${ }^{1}$. First descriptions by Wallenberg were in 1895 (clinical) and 1901 (autopsy findings).The lateral medullary syndrome (Wallenberg's syndrome) is most often caused by occlusion of the intracranial segment of the vertebral artery (VA), less commonly, it is caused by occlusion of the posterior inferior cerebellar artery (PICA).

The syndrome is characterized by sensory deficits affecting the trunk and extremities on the opposite side of the infarction and sensory deficits affecting the face and cranial nerves on the same side with the infarct. Specifically, there is a loss of pain and temperature sensation on the contralateral side of the body and ipsilateral side of the face. The crossed finding is diagnostic for the syndrome. Other clinical symptoms and signs are swallowing difficulties (Dysphagia) ${ }^{2}$, slurred speech, ataxia, facial pain, vertigo, nystagmus, Horner's syndrome, diplopia and possibly palatal myoclonus. The affected persons have dysphagia resulting from involvement of the nucleus ambigus as well as dysarthria. Damage to the spinal trigeminal nucleus causes absence of pain on the ipsilateral side of the face as well as absence corneal reflex.

1. Dr. Radheshyam Saha, FCPS (Medicine), MD (Neurology), Assistant Professor, Dept. of Neurology, FMC, Faridpur.

2. Dr. Samiul Alam, MBBS, Registrar, Dept. of Medicine, FMCH, Faridpur.

3. Dr. Md. Azmol Hossain, MBBS, Assistant Registrar, Dept. of Medicine, FMCH, Faridpur.

Address of Correspondence

Dr. Radheshyam Saha, FCPS (Medicine), MD (Neurology),

Assistant Professor, Dept. of Neurology, FMC, Faridpur.

Phone: +88-01711883080.
The spinothalamic tract is damaged, resulting in loss of pain and temperature sensation to the opposite side of the body. The damage to the cerebellum or the inferior cerebellar peduncle causes ataxia. Damage to the hypothalamo- spinal fibers disrupts sympathetic nervous system giving rise to Horner's syndrome. Nystagmus and vertigo result from involvement of vestibular nuclei. Onset is usually acute with severe vertigo. Palatal myoclonus may be due to involvement of the cranial trigeminal tract. Wallenberg's syndrome (WS) is caused by a stroke in one of the two arteries of the brainstem. The stroke associated with WS usually causes damage in the lateral medulla of the brainstem. It may also cause damage to the cerebellum. There is no specific treatment for WS. Treatment is symptomatic.

\section{Case report}

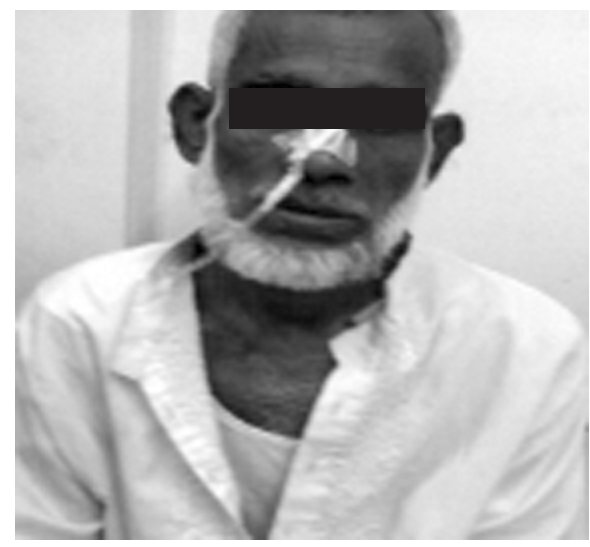

Figure: Mr. Ibrahim Mollah 50 years, patient of Wallenberg's syndrome. 
Mr. Ibrahim Mollah 50 years old person, non hypertensive, non diabetic, smoker from Adampur, Sadar Upazilla, Faridpur was admitted on 20-08-2008 in Faridpur Medical College Hospital with the complaints of sudden onset of dysphagia, dysarthria with nasal voice and ataxia of the gait. On examination, patient was conscious, well oriented, and co-operative. Speech was dysartharic with nasal voice. Patient also had right sided Horner's syndrome, loss of pain and temperature sensation on the right sided of the face, IX and $\mathrm{X}$ cranial nerves palsy on the right side and presence of cerebellar signs on the right side. There was loss of pain and temperature sensation on the left sided of the body. All deep tendon reflexes (DTR) and plantar reflexes were normal, pulse and BP, heart and lungs were also normal. On investigations; CT scan of the brain showed an infarct on the right side of the medulla, ECG- old anterior MI, Chest X-ray- mild cardiomegaly, CBC- no-abnormality, RBS- 6 m-mol/, $\mathrm{S}$. Creatinine- $1.2 \mathrm{mg} / \mathrm{L}, \quad \mathrm{S}$. Electrolytes- noabnormality.

\section{Discussion}

Lateral medullary syndrome is a uncommon stroke. We can diagnose the case clinically. Head imaging (CT/MRI of the brain) can confirm the diagnosis ${ }^{3-5}$. Lateral medullary syndrome is commonly caused by thrombosis or embolism of the VA or PICA. Here, the emboli coming from the heart as the patient had an attack of myocardial infarction (MI). Among the symptoms and sings, dysphagia is troublesome and has been reported in $51 \%$ to $94 \%{ }^{3}$. Patient has been widely accepted that in most cases the dysphagia in WS initially severe enough to require non-oral feeding but often improves rapidly, and the patient can return to oral feeding with in 1 to 2 months after the stroke $e^{1,6}$. Although in WS the lesion due to lateral medullary infarction is unilateral, its effect on oro-pharyngeal swallowing is bilateral ${ }^{7}$.

The Outlook for someone with WS depends upon the size and location of the area of the brainstem damaged by the stroke. Some individuals may see a decrease in their symptoms with in weeks or months following treatment. Others may be left with significant neurological disabilities for years after the initial symptoms appeared.

\section{References}

1. Kim H, Chung CS, Lee KH, Robbins J. Aspiration subsequent to a pure medullary infarction: lesion site, clinical variables and outcome. Arch neurol. 2005;57:478-483.

2. Khedr EM, Abo-Elfetoh N. Therapeutic role of rTms on recovery of dysphagia in patients with lateral medullary syndrome and brainstem infarction. $J$ Neurol Neurosurg Psychiatry 2010;81(5):495-9.

3. Sacco RL, Freddo L, Bello JA, Odel JG, Onesti ST, Mohr JP. Wallenberg's lateral medullary syndrome. Arch Neurol. 1993;50:609-14.

4. Kim JS. Pure lateral medullary infarction: clinical-radiological correlation of 130 acute, consecutive patients. Brain 2003;126(8):1864-1872.

5. Kim JS, Lee JH, Choi CG. Patterns of lateral medullary infarction: vascular lesion-magnatic resonance imaging correlation of 34 cases. Stroke 1998;29(3):645-652.

6. Logemann JA. Evaluation and treatment of swallowing disorders 2nd ed. Austin, Tex: Pro-Ed inc;1998.

7. Aydogdu I, Ertckin C, Tarlaci S, Turman B, Kiylioglu N, Secil Y. Dysphagia in lateral medullary syndrome (Wallenberg's syndrome). Stroke 2001;32:2081-2087. 